\title{
Comparação da vulnerabilidade de estudantes da escola pública e particular em relação ao HIV
}

\author{
HIV vulnerability comparison between public \\ and private high school students
}

\author{
Brigido Vizeu CAMARGO \\ Raquel Bohn BERTOLDO²
}

\begin{abstract}
Resumo
Os adolescentes fazem parte de uma população vulnerável à Síndrome da Imunodeficiência Adquirida, pois demandam emancipação, o que implica riscos. O presente estudo compara adolescentes de meios socioculturais distintos (escola pública - diurno e noturno - e privada) quanto ao conhecimento, comunicação, risco sobre a Síndrome da Imunodeficiência Adquirida e atitude quanto ao preservativo. Utilizou-se um survey com 1386 estudantes de ensino médio. O ambiente dos alunos do noturno é mais similar ao do adulto. Apesar de eles apresentarem atitudes positivas em relação ao uso do preservativo, essas não foram tão positivas quanto aquelas dos alunos do diurno. Apresentaram também mais problemas de conhecimento que os do diurno, estando tais problemas associados a atitudes menos positivas diante do preservativo, menor intenção em usá-lo, menor uso efetivo, e maior medo de contrair o vírus. O comportamento de risco dos alunos do turno noturno, associado a fatores cognitivos e ambientais, indica sua maior vulnerabilidade perante o Vírus da Imunodeficiência Adquirida.
\end{abstract}

Palavras-chave: AIDS; escola; vulnerabilidade.

\begin{abstract}
Theyouth is a vulnerable population to Acquired Immune Deficiency Syndrome, as they demand freedom for their emancipation and, as a consequence, risk behaviors. This study compares adolescents from different socio-cultural backgrounds (public - diurnal and nocturnaland private schools) about their Acquired Immune Deficiency Syndrome communication context, knowledge, risk behavior concerning Human Immunodeficiency Virus and attitudes towards the preservative. A survey was applied to a 1386 high school student's sample. The environment of the students from the nocturnal period is more similar to the adult's; even though they show positive attitudes, they are not as positive as the diurnal students. They also showed more problems regarding the knowledge of Acquired Immune Deficiency Syndrome, which is related to their less positive attitudes towards the preservative and intention to use, lower frequency of use and more fear of acquiring the Human Immunodeficiency Virus. This group's risky behavior associated to cognitive and environmental indicators show us its greater vulnerability regarding the Human Immunodeficiency Virus.
\end{abstract}

Key words: AIDS; school; vulnerability.

URV

1 Professor Doutor, Departamento de Psicologia, Laboratório de Psicossociologia da Comunicação e da Cognição Social, Universidade Federal de Santa Catarina. Campus Universitário, Trindade, 88040-970, Florianópolis, SC, Brasil. Correspondência para/Correspondence to: B.V. CAMARGO. E-mail: <bcamargo@cfh.ufsc.br>.

2 Bacharel em Psicologia. Florianópolis, SC, Brasil.

Apoio financeiro: $\mathrm{PIBIC/CNPq}$ 
Do início da década de 1980 até o ano de 2003, o Ministério da Saúde notificou 277154 casos de Síndrome da Imunodeficiência Adquirida (AIDS) no Brasil: 197340 homens e 79814 mulheres. Segundo dados recentes do Ministério da Saúde, tem havido uma desaceleração nas taxas de incidência de AIDS no conjunto do País, além de algumas tendências demográficas que seguem o perfil médio do brasileiro: heterossexualização (hoje existem mais heterossexuais do que homossexuais portadores do vírus no Brasil), feminilização e pauperização do portador do vírus da imunodeficiência adquirida (HIV) (Rua \& Abramovay, 2001).

Considerando que a latência do HIV é de aproximadamente dez anos, que a via sexual é a principal forma de transmissão do vírus, e que a faixa etária mais atingida pela manifestação da doença é a de 20 a 39 anos, é provável que a contaminação de grande parte dos atuais portadores tenha ocorrido na adolescência (Wuo, 2003).

A adolescência é uma fase caracterizada por profundas mudanças individuais e sociais. Ao adolescente já é permitido tomar decisões em vários aspectos de sua vida, inclusive na esfera sexual (Béria \& Barros, 1998). Comportamentos típicos dessa idade, como explorar o novo e experimentar riscos (Ayres, 1996), tornam os adolescentes uma população vulnerável ao HIV e, também, ideal para o investimento em educação.

Durante a adolescência ocorrem a aquisição e a consolidação de hábitos que, muitas vezes, perdurarão pela vida do indivíduo, como o hábito de fumar, ingerir álcool ou, especificamente, engajar-se em relações sexuais desprotegidas.

As práticas relativas à sexualidade são apreendidas com os outros componentes dos grupos sociais de pertença, os quais modulam também sua própria expressão (Parker, 1991). Assim, não somente questões racionais são levadas em conta no momento da tomada de decisão em matéria de sexualidade, mas valores culturais e modelos de conduta socialmente construídos. Wuo (2003) afirma que para a compreensão do comportamento de risco há a necessidade de conhecer: a) a posição hierárquica do risco para a pessoa; b) a intersubjetividade na tomada de decisão e c) o contexto de ocorrência do risco.

Invariavelmente, a posição da mulher no sexo, como estudos têm apresentado (Nicolson \& Burr, 2003), continua sendo a de satisfazer o parceiro, posicionando-se de forma passiva nas relações com o sexo masculino. Assim, a decisão de usar ou não o preservativo fica sujeita ao exercício do poder, intrínseco às relações de gênero. Giacomozzi (2004) ressalta a submissão da mulher, pois, no momento de negociar o uso do preservativo, muitas delas se sentem pressionadas a corresponder às expectativas dos parceiros, influenciadas pelos valores sociais vigentes.

A sexualidade tem significação bastante diversa para homens e mulheres. Béria, Oliveira e Carret (1998) encontraram evidências dessa diferença quando constataram que as informações oferecidas aos adolescentes no contexto doméstico divergem no seu conteúdo: com as moças abordam-se questões relacionadas à virgindade e à gravidez, enquanto com os rapazes questões referentes à relação sexual e à AIDS.

Pesquisas anteriores com estudantes adolescentes (Camargo, 1997; Camargo, Botelho \& Souza 2001; Camargo, Hias \& Machado, 2002) constataram que, predominantemente, as meninas têm atitudes mais positivas em relação ao preservativo que os meninos. Além disso, Camargo, Hias e Machado (2002) observaram que as estudantes têm melhor desempenho na restituição mnemônica da informação sobre AIDS.

O conceito de atitude é importante para o estudo do comportamento de prevenção, pois fornece pistas sobre o comportamento do indivíduo quando ele está diante da AIDS. A atitude social pode ser definida como uma organização duradoura de crenças e cognições em geral, dotada de carga afetiva pró ou contra um objeto social definido, que predispõe a uma ação coerente com as cognições e afetos referentes a esse objeto (Rodrigues, Assmar \& Jablonski, 1999).

A comunicação também desempenha papel fundamental na prevenção à AIDS. O conhecimento que se tem sobre um objeto depende da experiência direta que se tem com ele, mas, cada vez mais, depende também da experiência indireta, aquela adquirida pela informação ou por outras pessoas (Camargo et al., 2001). A conversa sobre sexualidade permite o compartilhamento de informações e experiências acerca desse aspecto da vida e, portanto, consiste em uma importante fonte de conhecimento. A comunicação permite o fortalecimento de atitudes e modelos de conduta, uma vez que dissemina informação e valores (Rodrigues, Assmar \& Jablonski, 1999). 
No entanto estudos já mencionados (Camargo, 1997; Camargo et al., 2002) têm mostrado que nem sempre o conhecimento das pessoas sobre a AIDS corresponde às suas intenções de adotar um comportamento preventivo.

Tinsley, Lees e Sumartojo (2004), avaliando a perspectiva da família na comunicação, observaram que a comunicação entre pais e filhos estava positivamente relacionada a condutas preventivas no adolescente, e que a comunicação franca e aberta tornaria os filhos mais receptivos aos padrões de comportamento e valores propostos pelos pais. Observando a influência de diferenças no padrão familiar de comunicação e, por conseguinte, no comportamento preventivo, os pesquisadores mencionados constataram que os euro-americanos, mais que os afro-americanos, latino-americanos e famílias de baixa renda, estabelecem comunicação sobre HIV e sexualidade dentro da família, dispondo esses adolescentes de melhores habilidades cognitivo-comportamentais para lidar com sua sexualidade.

Por outro lado, a experiência anterior direta com um objeto de atitude influencia de forma acentuada o próprio posicionamento da pessoa perante aquele objeto. Segundo Fazio e Zanna (1981), as atitudes que se constroem com base na experiência direta são mais preditoras do comportamento do que as que se baseiam em experiência indireta.

Bandura (1997) pontua dois outros fatores importantes para a ocorrência de um comportamento preventivo: a crença da pessoa na sua auto-eficácia em poder realizá-lo e a expectativa em relação aos resultados esperados advindos desse comportamento (diminuição do risco). Em relação ao adolescente sexualmente ativo, podemos prever que aqueles que estão em maior risco não se percebem como tal, pois aumentam a confiança nas suas respostas diante do meio (percepção de auto-eficácia), diminuindo assim o stress perante situações cotidianas referentes à AIDS (Bandura, 1997; Rodrigues Assmar \& Jablonski, 1999). O medo está relacionado à estimativa do risco a que uma pessoa se submete, à sua percepção de auto-eficácia, e também à sua percepção da situação em que está envolvida e dos recursos que pode disponibilizar (Lima, 1998). Tratando-se de comportamento preventivo diante do HIV, o medo está relacionado ao risco percebido (de não usar o preservativo), à capacidade percebida de que pode se prevenir (auto-eficácia) e ao recurso disponível (preservativo).

O conceito de vulnerabilidade como "... suscetibilidade dos indivíduos e populações a agravos ou riscos" (Ayres, França, Calazans \& Saletti, 1999) surgiu como uma tentativa de ampliar a abordagem comportamentalista que associa a prevenção no indivíduo com as noções de comportamento de risco e grupo de risco. Ele foi primeiramente formulado por Mann (1993) e tinha como objetivo estabelecer um quadro de referência para a avaliação da vulnerabilidade ao HIV que fornecesse critérios aplicáveis desde o nível individual até o plano nacional de prevenção à AIDS.

A AIDS é uma doença cuja transmissão envolve aspectos comportamentais, cognitivos, emocionais e culturais que são de ordem complexa. As medidas preventivas orientadas para a totalidade da população provaram ter pouca eficácia diante de grupos específicos, tais como o adolescente, o de mulheres casadas, dentre outros. A consideração das diferenças entre os grupos sociais é necessária para qualquer atividade bem-sucedida de prevenção. O conceito de vulnerabilidade contribui para a mudança do foco do problema: do indivíduo para o seu sistema de relações. Isso explica em parte o padrão atual de disseminação da doença entre as camadas mais populares e os setores mais destituídos de poder dentro da nossa sociedade (Ayres et al., 1999). O conceito é dividido em três planos interdependentes de apreensão da vulnerabilidade: (1) comportamento pessoal; (2) contexto social e (3) programa nacional de combate à AIDS.

Nesta pesquisa a vulnerabilidade estaria relacionada à escola freqüentada, na medida em que, no Brasil, cada tipo de instituição escolar atende alunos de bases socioeconômicas diferentes. No Brasil, mais que em outros países da América Latina, a escola constitui um produto social desigualmente distribuído (Akkari, 2001). Dessa forma, o tipo de escola e as desigualdades na condição de acesso ao ensino de qualidade já indicam a diferenciação do nível socioeconômico das famílias dos estudantes da rede de ensino público (municipal ou estadual). Akkari (2001) traça um panorama da desigualdade do sistema educacional brasileiro: há uma grande mobilidade entre as redes particular e pública de ensino, entretanto ela é "estreitamente vinculada ao 
poder de compra. As classes populares têm uma única escolha - a das escolas públicas municipais ou estaduais" (p.167). O sistema educacional brasileiro é caracterizado por uma grande rede pública, que acolhe a maioria dos alunos, e uma rede particular, elitista, freqüentada exclusivamente pelas classes privilegiadas.

O conceito de qualidade na educação foi trabalhado por Casassus (2002), que, além da avaliação de rendimento, preocupou-se em averiguar o ambiente externo do aluno. Cada ambiente institucional, privado ou público, da zona rural ou urbana, possui a sua especificidade, cada aluno convive e constrói suas representações em ambiente cultural e socioeconômico diferente. Além disso, a escola pública possui aspectos materiais, atores (estudantes, docentes, pais ou responsáveis e diretores), clima organizacional e pedagogia diferentes daqueles encontrados na rede privada.

Assim como há dicotomia entre escolas (pública ou particular) quanto ao nível socioeconômico, há uma diferenciação entre os períodos diurno e noturno observados na escola pública. Essa diferenciação interna dá-se pela necessidade de os alunos desempenharem atividades remuneradas. Mesmo vinte anos atrás, Rosenberg (1986) já observava que a renda média familiar entre os alunos do turno noturno é menor do que entre os do diurno, e ainda que o número de alunos de baixa renda do período noturno era maior que o dobro que o dos alunos do período diurno. Disparidades quanto à proporção da população economicamente ativa na escola foram verificadas por Camargo et al. (2001) entre estudantes de três cidades catarinenses (Balneário Camboriú, Florianópolis e Itajaí): 51,2\% dos alunos do turno diurno de escolas públicas já haviam desenvolvido ou desenvolvia, no momento da pesquisa, alguma atividade remunerada, enquanto o percentual encontrado entre os alunos do turno noturno chegou a $72,8 \%$ e foi de apenas $26,6 \%$ entre os estudantes da rede particular de ensino.

Esta pesquisa analisou comparativamente a vulnerabilidade dos alunos da escola pública e privada diante do HIV. A vulnerabilidade foi considerada por meio de indicadores a ela relacionados, tais como: comunicação, informação, atitudes, ambiente, experiência e afetividade.

\section{Método}

Trata-se de uma pesquisa comparativa entre a escola pública e a privada. Os dados são provenientes de um levantamento de dados com 1386 estudantes que cursavam o ensino médio das cidades de Florianópolis ( $n=858)$, Itajaí $(n=329)$ e Balneário Camboriú ( $n=199)$ no final de 2000. Dos 1386 alunos, $59,4 \%$ eram do sexo feminino; $41,2 \%$ estudavam no período diurno em escolas públicas, $27,8 \%$ no período noturno em escolas públicas e 31,0\% no diurno em escolas particulares. A técnica de amostragem empregada foi a por conglomerados, buscando respeitar a proporção de alunos matriculados por cidade, por tipo de escola e por turno.

Para a coleta de dados foi utilizado um questionário anônimo, aplicado coletivamente, composto por cinco grupos de questões: 1) características pessoais dos participantes, tais como idade, sexo, tipo de escola em que estuda, ambiente social, experiência de trabalho, experiência amorosa e sexual, e contexto de comunicação sobre a sexualidade; 2) conhecimento relacionado à $\mathrm{AIDS}^{3}$; 3) percepção e sentimentos em relação ao risco de infecção, e julgamento da importância e do perigo da doença; 4) atitudes: intenção de adoção de condutas preventivas, e atitudes diante do preservativo (para isso utilizou-se uma escala tipo Likert de 4 pontos, composta de 12 itens com $\alpha=0,75)$; e 5) comportamentos arriscados e de proteção em relação ao HIV.

A equipe fez contato com a direção de cada escola, apresentando um protocolo de pesquisa em conformidade com os preceitos éticos vigentes (anonimato, participação voluntária, ciência dos objetivos da pesquisa, cuidados com a integridade física, psicológica e social do participante, etc.) e solicitou autorização prévia para sua realização. Considerando

$\operatorname{rrr}$

3 Estimado a partir das respostas corretas a sete possíveis modos de transmissão do HIV: nas relações sexuais, nos banheiros públicos, injetando droga com a seringa de outro, recebendo sanque (transfusão sangüínea), pela picada de um mosquito, estando internado num mesmo setor do hospital que uma pessoa contaminada e doando seu sangue. Desse modo o escore variava de 0 a 7 pontos. 
que a direção das escolas estudadas já tinha autorização dos pais para esse tipo de atividade, ela foi obtida após a concordância com o protocolo apresentado. Além disso, foi realizada uma palestra de dessensibilização ao final da coleta em cada sala de aula.

Foi realizada uma análise comparativa dos dados dos estudantes das escolas pública (período diurno e noturno) com os dos alunos da escola particular, por meio de tabelas de contingência (testes estatísticos não paramétricos) e de comparação de médias (teste " $t$ " de Student e análise de variância simples). Assim foi possível observar a relação entre as questões em função de contextos socioculturais distintos. Utilizou-se para tal fim o programa estatístico SPSS.

\section{Resultados e Discussão}

A média de idade dos alunos participantes da amostra analisada nesta pesquisa foi de 17 anos e 3 meses. A média observada na escola pública diurna foi de 17 anos e 4 meses, na noturna foi de 17 anos e 10 meses, e na escola particular, 16 anos e 8 meses. A escola particular possui alunos com média de idade significativamente menor ( $F=54,8 \mathrm{gl}=2 p<0,001)$ que aquelas observadas na rede pública. É importante indicar que os alunos que ingressam no ensino fundamental com 6 anos, em média, atingem a 2a série do ensino médio com 16 anos.

Apesar de a maioria da amostra morar com os pais (72,1\%), existe diferença significativa entre os grupos de alunos estudados. A percentagem é menor entre os alunos da escola pública noturna $(63,1 \%)$ do que da diurna $(74,1 \%)$ e da particular $(77,6 \%)\left(\chi^{2}=32,043 \mathrm{gl}=8\right.$ $p<0,001)$. O exercício da atividade remunerada por parte dos alunos apresenta diferenças significativas entre as subamostras: no grupo de alunos do turno noturno, 72,8\% já exerceram ou exercem esse tipo de atividade, ao passo que entre os alunos do turno diurno, a percentagem foi de $51,2 \%$, e entre os alunos da escola particular, $26,6 \%\left(\chi^{2}=178,102 p<0,001\right)$.

A pesquisa constatou também que 93,6\% dos alunos da escola particular, 91,6\% dos do turno diurno da escola pública, e 83,2\% dos do turno noturno afirmaram possuir um grupo de amigos $\left(\chi^{2}=27,060\right.$, $g \mid=2, p<0,001)$. Os alunos do período noturno freqüen- tam ambientes de trabalho, o que os aproxima do adulto, estabelecendo relações que são, muitas vezes, diversas daquelas encontradas no contexto escolar, como as relações de amizade. Desse modo, a situação socioeconômica parece exercer influência sobre a rede social do aluno, delimitando seu universo comunicacional e, conseqüentemente, informativo e afetivo.

Os adolescentes encontram-se em fase de iniciação sexual; por isso, a amostra divide-se entre os alunos que já experimentaram a relação sexual com penetração e os que não a experimentaram. A diferença entre os grupos estudados mostrou-se significativa: 64,5\% dos alunos do turno noturno da escola pública já tiveram ao menos uma relação sexual com penetração, $49,8 \%$ dos alunos do turno diurno e $42,6 \%$ dos alunos da escola particular $\left(\chi^{2}=44,548 \mathrm{gl}=6 \mathrm{p}<0,001\right)$. Essas relações têm como contexto principal o namoro, uma vez que a quantidade de adolescentes com namoradas (os) que declarou ter tido relações nos últimos 12 meses $(66,1 \%)$ foi maior que o dobro daquela verificada entre os que não têm namorada (o) (30,2\%). A relação entre namoro e escola apresenta-se assim distribuída: 39,2\% dos alunos do período noturno da escola pública namoram, 36,8\% dos alunos do turno diurno e 28,3\% dos alunos da particular $\left(\chi^{2}=12,394 \mathrm{gl}=2 p<0,002\right)$. Os alunos da escola pública noturna possuem maior experiência sexual que os alunos das outras amostras, além de estarem mais freqüentemente envolvidos em relacionamentos afetivo-amorosos. O envolvimento sexual dos alunos do noturno evidencia o maior risco em matéria de doenças sexualmente trans-missíveis e AIDS, acrescido pelas condições de educação em saúde disponíveis para essa população.

Quando conversam sobre sexualidade, a maioria dos que têm namorado(a) tem esse tipo de comunicação com seus parceiros (83,09\%). Entretanto, menos da metade (34,9\%) namora, o que faz com que os amigos, na amostra como um todo, sejam apontados como os principais interlocutores para esse assunto: $77,8 \%$ dos estudantes declararam conversar com os amigos sobre sexualidade. Quanto à comunicação sobre sexualidade com os pais, ela apareceu em maior proporção entre os alunos das escolas particulares (50,8\%), seguidos pelos alunos do diurno da escola pública $(43,9 \%)$ e pelos alunos do noturno $(41,8 \%)\left(\chi^{2}=7,598 \mathrm{gl}=2 p<0,02\right)$. Esse achado corrobora a colocação de Di lorio, Kelley e 
Hockenberry-Eaton (1999), de que a comunicação sobre assuntos da esfera sexual com a família está ligada a comportamentos familiares mais tradicionais.

\section{Percepção de problemas pelos adolescentes e condutas de risco}

O posicionamento dos alunos em relação aos problemas que enfrentam no seu cotidiano nos fornece indícios sobre a percepção que têm sobre as suas vulnerabilidades. Foram apresentados nove problemas que atingem os adolescentes (Tabela 1), dos quais dois apresentaram diferenças significativas entre as subamostras: o desemprego e o suicídio. Na escola pública noturna e diurna, respectivamente $92,5 \%$ e $91,3 \%$ dos alunos consideraram o desemprego como problema importante, enquanto na escola particular essa percentagem foi de $83 \%\left(\chi^{2}=22,497 \mathrm{gl}=2 p<0,001\right)$. Esse resultado é condizente com a realidade sociocultural dos alunos, já que entre as classes média e alta o desemprego representa uma ameaça menos grave para as famílias. As condutas de risco dos alunos têm relação com o risco específico de exposição ao HIV, e elas apresentam diferenças entre as três subamostras consideradas (Tabela 1).

Observa-se que, nos últimos doze meses, mais da metade dos alunos da escola pública faltaram à aula sem motivo (53,7\% do diurno e 51,7\% do noturno), enquanto na escola particular essa percentagem foi de $42,9 \%\left(\chi^{2}=12,171 \mathrm{gl}=2 p<0,01\right)$.

O uso do preservativo é a conduta que mais interessa à prevenção da AIDS. Entre os alunos que tiveram ao menos uma relação sexual com penetração nos últimos 12 meses, mais da metade, em se tratando de escola pública, deixou de usar o preservativo em algum momento (59,8\% do noturno e 50,4\% do diurno), enquanto a proporção foi de 40,5\% na escola particular $\left(\chi^{2}=13,076 \mathrm{gl}=2 p<0,001\right)$.

Quanto ao uso de drogas os alunos foram questionados especificamente sobre o uso de maconha. Os resultados mostram que as escolas particulares obtiveram significativamente maior percentagem de alunos que usaram a droga nos últimos doze meses (13,8\%), enquanto os alunos das escolas públicas do período noturno (10,1\%) e diurno (9,1\%) apresentaram uma proporção menor de alunos que usaram maconha $\left(\chi^{2}=5,786 \mathrm{gl}=2 p<0,05\right)$.

O consumo de álcool é considerado comportamento de risco pelas alterações cognitivas que tornam o indivíduo mais vulnerável a outras situações de risco, além de ser o consumo em si um comportamento auto-destrutivo. Os resultados apresentaram diferenças significativas entre os grupos de alunos: $38,7 \%$ dos alunos da escola particular afirmaram ter "ficado bêbado" nos últimos doze meses, enquanto 35,1\% dos do turno noturno e $28,1 \%$ do turno diurno da escola pública afirmaram ter passado por isso $\left(\chi^{2}=12,99 \mathrm{gl}=2\right.$ $p<0,01)$. Esses dados acima reportados deixam clara a relação entre risco incorrido e ambiente sociocultural.

\section{Atitudes e uso do preservativo}

As atitudes dos alunos diante do preservativo foram positivas; eles apresentaram uma média de 3,09

Tabela 1. Tipos de risco apresentados pelos alunos segundo o tipo de escola freqüentada (rede de ensino médio de Florianópolis, Itajaí e Balneário Camboriú, 2000) (n=1386).

\begin{tabular}{|c|c|c|c|c|}
\hline \multirow{2}{*}{ Riscos admitidos nos últimos 12 meses } & \multicolumn{3}{|c|}{ Alunos (\%) } & \\
\hline & Escola particular & Escola pública - diurno & Escola pública-noturno & \\
\hline Faltar às aulas sem motivo & 42,9 & $53,7^{*}$ & 51,7 & $\chi^{2}=12,17 \quad g l=2 p<0,01$ \\
\hline Relação sexual sem pílula & 73,9 & 74,4 & 68,2 & $\chi^{2}=2,77 g l=2 p=0,25$ \\
\hline Relação sexual sem preservativo & 40,5 & 50,4 & $59,8^{*}$ & $\chi^{2}=13,07 \quad g l=2 p<0,001$ \\
\hline Fumar maconha & $13,8^{*}$ & 9,1 & 10,1 & $\chi^{2}=5,78 \quad g l=2 p<0,05$ \\
\hline Brigar & 16,1 & 12,2 & 14,0 & $\chi^{2}=3,03 \quad g l=2 p<0,22$ \\
\hline Quebrar as coisas dos outros & $31,5^{*}$ & 24,1 & 23,4 & $\chi^{2}=9,02 \quad g l=2 p<0,01$ \\
\hline Ficar bêbado & $38,7^{*}$ & 28,1 & 35,1 & $\chi^{2}=12,99 \mathrm{gl}=2 p<0,01$ \\
\hline Dirigir moto sem capacete & 6,1 & $11,9^{*}$ & 11,2 & $\chi^{2}=10,30 \mathrm{gl}=2 p<0,01$ \\
\hline
\end{tabular}

*Escola com maior risco estatisticamente significativo. 
em uma escala de quatro pontos. As médias encontradas nas escolas foram: 3,04 na pública noturna, 3,10 na pública diurna e 3,13 na particular. Os alunos do turno noturno da escola pública são significativamente menos favoráveis ao uso do preservativo que aqueles do período diurno da escola pública e da escola particular $\left(F_{2,1383}=7,95, p<0,001\right)$. Entre os alunos com vida sexual ativa, o comportamento relativo ao uso do preservativo foi significativamente diferente entre os tipos de escola e turnos de estudo; na escola pública, no período noturno 35,4\% dos alunos afirmam tê-lo usado em todas as relações, no período diurno, 47,6\%, e na escola particular, 58,6\% dos alunos $\left(\chi^{2}=18,410 \mathrm{gl}=2 p<0,001\right)$. Globalmente, observou-se incoerência entre as atitudes claramente favoráveis e o comportamento preventivo do uso de preservativo parcialmente adotado pelos adolescentes. No entanto quanto maior a média, por tipo de escola, na escala de atitude mais alunos daquela escola declararam ter usado o preservativo em todas as relações.

Foi também observado que os alunos com experiência sexual tinham atitudes menos positivas $(3,06)$ que os alunos sem experiência sexual $(3,13)$. Parece que a experiência direta fornece elementos para o adolescente compreender a complexidade da gestão da racionalidade (decisão e execução do sexo seguro) em uma situação fortemente emocional.

O namoro está associado ao não uso do preservativo em todos os tipos de escola, embora os alunos da escola pública noturna abandonem mais facilmente o preservativo que os alunos que estudam no período diurno da escola pública ou particular (Tabela 2).

As atitudes sustentam um comportamento que é contextualizado, portanto as pessoas podem se comportar de modo conflitante em relação ao seu objeto atitudinal dependendo da exigência do ambiente (componente comportamental das atitudes). Observa-se que adolescentes que namoram geralmente abandonam o uso do preservativo no curso do relacionamento. Gebhart, Kuyper e Greunsven (2003) colocam a intimidade como fator correlacionado negativamente com o uso do preservativo, assim como proximidade emocional e confiança, pois diminuem a necessidade de proteção.

\section{Conhecimento sobre AIDS}

Das sete questões de conhecimento sobre a AIDS somente em duas foram observadas diferenças significativas entre as subamostras quanto à informação dos alunos (Tabela 3).

Os resultados mostraram que os alunos da escola particular possuem maior conhecimento, ao menos no que diz respeito aos meios de transmissão do HIV, do que aqueles da escola pública diurna e noturna. Constatou-se ainda que mais de $78 \%$ dos alunos que

Tabela 2. Relação entre namoro e abandono do uso do preservativo (rede de ensino médio de Florianópolis, Itajaí e Balenário Camboriú, 2000) $(n=568)^{*}$.

\begin{tabular}{|c|c|c|c|c|c|c|c|c|}
\hline \multirow{3}{*}{ Escolas } & & & \multicolumn{6}{|c|}{ Você tem namorado (a) } \\
\hline & & & \multicolumn{2}{|c|}{ Sim } & \multicolumn{2}{|c|}{ Não } & \multicolumn{2}{|c|}{ Total } \\
\hline & & & $\mathrm{n}$ & $\%$ & n & $\%$ & $n$ & $\%$ \\
\hline \multirow[t]{3}{*}{ Pública noturna } & Você sempre usou o preservativo? & Sim & 28 & 25,9 & 42 & 48,8 & 70 & 36,0 \\
\hline & & Não & 80 & 74,1 & 44 & 51,2 & 124 & 64,0 \\
\hline & $\chi^{2}=9,9 \mathrm{gl}=1 p<0,01$ & Subtotal & 108 & 100,0 & 86 & 100,0 & 194 & 100,0 \\
\hline \multirow[t]{3}{*}{ Pública diurna } & Você sempre usou o preservativo? & Sim & 45 & 38,1 & 58 & 56,3 & 103 & 46,6 \\
\hline & & Não & 73 & 61,9 & 45 & 43,7 & 118 & 53,4 \\
\hline & $\chi^{2}=7,3 \mathrm{gl}=1 \quad p<0,01$ & Subtotal & 118 & 100,0 & 103 & 100,0 & 221 & 100,0 \\
\hline \multirow[t]{4}{*}{ Particular } & Você sempre usou o preservativo? & Sim & 37 & 48,1 & 53 & 69,7 & 90 & 58,8 \\
\hline & & Não & 40 & 51,9 & 23 & 30,3 & 63 & 41,2 \\
\hline & $\chi^{2}=6,6 \mathrm{gl}=1 \quad p<0,01$ & Subtotal & 77 & 100,0 & 76 & 100,0 & 153 & 100,0 \\
\hline & $\chi^{2}=26,1 \mathrm{gl}=1 \quad p<0,01$ & Total & 303 & 53,3 & 265 & 46,6 & 568 & 100,0 \\
\hline
\end{tabular}

*Somente os alunos que tiveram ao menos uma relação sexual com penetração. 
Tabela 3. Percentagens das respostas erradas dos alunos a questões de conhecimento sobre a AIDS e tipo de escola freqüentada (rede de ensino médio de Florianópolis, Itajaí e Balneário Camboriú, 2000**

\begin{tabular}{|c|c|c|c|c|c|c|c|c|c|}
\hline \multirow{2}{*}{ Escolas } & \multirow{2}{*}{ Alunos } & \multicolumn{2}{|c|}{ Pública Diurna } & \multicolumn{2}{|c|}{ Pública Noturna } & \multicolumn{2}{|c|}{ Particular } & \multicolumn{2}{|c|}{ Total } \\
\hline & & $n$ & $\%$ & $n$ & $\%$ & $n$ & $\%$ & $n$ & $\%$ \\
\hline $\begin{array}{l}\text { Transmite-se AIDS recebendo sangue? } \\
\chi^{2}=17,956 \mathrm{gl}=2 \quad p<0,001\end{array}$ & $\begin{array}{l}\text { Responderam } \\
\text { incorretamente à questão } \\
\text { e número }\end{array}$ & 45 & 7,8 & 55 & 14,3 & 33 & 7,7 & 133 & 9,6 \\
\hline \multirow[t]{2}{*}{$\begin{array}{l}\text { Transmite-se AIDS estando internado no } \\
\text { mesmo setor hospitalar que uma pessoa } \\
\text { contaminada? } \\
\chi^{2}=13,826 \mathrm{gl}=2 \quad p<0,001\end{array}$} & $\begin{array}{l}\text { Responderam } \\
\text { incorretamente à questão } \\
\text { e número }\end{array}$ & 119 & 20,8 & 85 & 22,1 & 57 & 13,3 & 261 & 18,8 \\
\hline & Número total de sujeitos & \multicolumn{2}{|c|}{572} & \multicolumn{2}{|c|}{385} & \multicolumn{2}{|c|}{429} & \multicolumn{2}{|c|}{1386} \\
\hline
\end{tabular}

*Foram apresentadas apenas as questões que obtiveram diferenças significativas entre as escolas; e excluídas as outras questões, a saber: 1) nas relações sexuais; 2) nos banheiros públicos; 3) injetando droga com a seringa de outro; 4) recebendo sangue (transfusão sangüínea); 5) pela picada de mosquito.

responderam às perguntas incorretamente se consideram bem informados acerca da AIDS. Ao avaliar a sua informação como suficiente para uma tomada de decisão, o comportamento manifesto difere daquele em que a informação é julgada insuficiente, o que implica o aumento do risco diante do HIV.

No conjunto dos participantes, observou-se relação entre informação e percepção da auto-eficácia do comportamento de prevenção. O escore médio nas questões de conhecimento sobre os modos de transmissão do HIV dos alunos que afirmaram que consideram proteger-se da AIDS foi um pouco maior $(5,96)$ que o dos alunos que acreditavam não se proteger o suficiente $(5,70)(t=3,59 ; g l=1183 ; p<0,001)$. A informação de que o indivíduo dispõe sobre o objeto de ação permite que ele se comporte de modo mais condizente com a realidade, pois está informado sobre as suas conseqüências. A percentagem de alunos com vida sexual ativa que considera se proteger do HIV também difere segundo o tipo de escola: 70,4\% dos alunos da escola particular, 59,2\% dos alunos da escola $\therefore$ pública diurna e $52,1 \%$ dos alunos do turno noturno $\left.\sum^{2}=14,675 \mathrm{gl}=4 \mathrm{p}=0,005\right)$.

A percepção de auto-eficácia, assim como a intenção de adoção de comportamento preventivo, não é em si preventiva, mas sua influência num contexto é importante. Nesse sentido, pode-se relacionar a percepção de auto-eficácia ao uso do preservativo, e nesse caso se presume, a partir da hipótese de que o preservativo promove proteção ao HIV, que esse tipo de percepção está diretamente relacionado ao uso do preservativo.
É importante notar que, entre os alunos que não usaram o preservativo, aqueles do turno noturno, mais que os das outras escolas, afirmaram não se proteger o suficiente da AIDS. Muito embora os alunos do período noturno mais freqüentemente tenham deixado de usar o preservativo, eles também reconhecem o risco da situação, sendo os alunos da escola particular os que menos percebem o risco diante do HIV (Tabela 4).

A intenção de adoção de um comportamento está intimamente relacionada à atitude para com o objeto daquele comportamento, uma vez que a base cognitiva, a emocional e a comportamental são as mesmas. A partir da comparação das médias das atitudes em relação ao preservativo, pudemos observar nos alunos do turno diurno (da escola pública ou da particular) que suas atitudes são mais favoráveis (apresentando diferenças estatisticamente significativas) quando eles declaram ter intenção de usá-lo do que quando não declaram tal intenção (escola pública diurna: $t=4,89 ; g l=568 ; p<0,001$; escola particular: $t=2,84 ; g l=424, p<0,01)$. Já os alunos do noturno não apresentaram médias significativamente diferentes em função da intenção de usar o preservativo $(t=1,65$; $g l=381 ; p=0,10$.

A intenção de usar o preservativo foi maior entre os alunos da escola particular em comparação aos alunos da escola pública. Em se tratando da escola pública, observou-se relação entre a intenção e o efetivo uso do preservativo (Tabela 5). 
Tabela 4. Relação entre não uso do preservativo e percepção da auto-eficácia, segundo o tipo de escola (rede de ensino médio de Florianópolis, Itajaí e Balneário Camboriú, 2000) $(n=567)^{*}$.

\begin{tabular}{|c|c|c|c|c|c|c|c|c|}
\hline \multirow{3}{*}{ Escolas } & & & \multicolumn{6}{|c|}{ Você sempre usou o preservativo? } \\
\hline & & & \multicolumn{2}{|c|}{ Sim } & \multicolumn{2}{|c|}{ Não } & \multicolumn{2}{|c|}{ Total } \\
\hline & & & $n$ & $\%$ & $n$ & $\%$ & $\mathrm{n}$ & $\%$ \\
\hline \multirow[t]{3}{*}{ Pública noturna } & Você se protege o suficiente da AIDS? & $\operatorname{sim}$ & $46^{* *}$ & 65,7 & 49 & 39,5 & 95 & 49,0 \\
\hline & & Não/não sei & 24 & 34,3 & 75 & 60,5 & 99 & 51,0 \\
\hline & $\chi^{2}=11,3 \mathrm{gl}=1 p<0,001$ & Subtotal & 70 & 100,0 & 124 & 100,0 & 194 & 100,0 \\
\hline \multirow[t]{3}{*}{ Pública diurna } & Você se protege o suficiente da AIDS? & $\operatorname{sim}$ & 75 & 72,8 & 53 & 44,9 & 128 & 58,0 \\
\hline & & Não/não sei & 28 & 27,2 & 65 & 55,1 & 93 & 42,0 \\
\hline & $\chi^{2}=16,4 \mathrm{gl}=1 p<0,001$ & Subtotal & 103 & 100,0 & 118 & 100,0 & 221 & 100,0 \\
\hline \multirow[t]{4}{*}{ Particular } & Você se protege o suficiente da AIDS? & Sim & 72 & 80,0 & 30 & 48,4 & 102 & 67,1 \\
\hline & & Não/não sei & 18 & 20,0 & 32 & 51,6 & 50 & 32,9 \\
\hline & $\chi^{2}=15,2 g \mid=1 p<0,001$ & Subtotal & 90 & 100,0 & 62 & 100,0 & 152 & 100,0 \\
\hline & $\chi^{2}=51,7 \mathrm{gl}=1 p<0,001$ & Total & 263 & 46,4 & 304 & 53,6 & 567 & 100,0 \\
\hline
\end{tabular}

*Somente os alunos que tiveram ao menos uma relação sexual com penetração nos últimos 12 meses; ** Os números entre parênteses indicam a freqüência absoluta dos participantes.

Tabela 5. Relação entre a intenção dos alunos em usar o preservativo e a sua efetiva utilização (rede de ensino médio de Florianópolis, Itajaí e Balneário Camboriú - 2000) $(n=415)^{*}$.

\begin{tabular}{|c|c|c|c|c|c|c|c|c|}
\hline \multirow{3}{*}{ Escolas } & & & \multicolumn{6}{|c|}{ Você sempre usou o preservativo? } \\
\hline & & & \multicolumn{2}{|c|}{ Sim } & \multicolumn{2}{|c|}{ Não } & \multicolumn{2}{|c|}{ Total } \\
\hline & & & $n$ & $\%$ & $\mathrm{n}$ & $\%$ & $\mathrm{n}$ & $\%$ \\
\hline \multirow[t]{3}{*}{ Pública diurna } & Você tem a intenção de usar o & Sim & 99 & 96,1 & 97 & 82,2 & 196 & 88,7 \\
\hline & preservativo no futuro? & Não/pode ser & 4 & 3,9 & 21 & 17,8 & 25 & 11,3 \\
\hline & $\chi^{2}=9,3 \mathrm{gl}=1 p<0,01$ & Subtotal & 103 & 100,0 & 118 & 100,0 & 221 & 100,0 \\
\hline \multirow[t]{3}{*}{ Pública noturna } & $\begin{array}{l}\text { Você tem a intenção de usar o } \\
\text { preservativo no futuro? }\end{array}$ & Sim & 67 & 95,7 & 96 & 77,4 & 163 & 84,0 \\
\hline & & Não/pode ser & 3 & 4,3 & 28 & 22,6 & 31 & 16,0 \\
\hline & $\chi^{2}=9,8 \mathrm{gl}=1 p<0,01$ & Subtotal & 70 & 100,0 & 124 & 100,0 & 194 & 100,0 \\
\hline Total & $\chi^{2}=22,7 \mathrm{gl}=1 p<0,01$ & Total & 173 & 41,7 & 242 & 58,3 & 415 & 100,0 \\
\hline
\end{tabular}

* Somente os alunos das escolas públicas que tiveram ao menos uma relação sexual com penetração. Entre os alunos da escola particular não houve diferença significativa.

Os alunos que declararam ter intenção de usar o preservativo são mais numerosos do que os que não declaram esse tipo de intenção. No entanto, os alunos do período noturno que declararam essa intenção são menos numerosos do que os do diurno. Quanto aos alunos da escola particular, eles são mais numerosos que os da escola pública (em torno de 90\%) em declarar ter intenção de usar sistematicamente o preservativo nas suas relações sexuais nos últimos doze meses, independente de já tê-lo feito ou não.
Observou-se que, entre os alunos da escola pública diurna e particular, os que mais têm medo são aqueles que não crêem que se protegem suficientemente da AIDS. Portanto, nesses dois tipos de alunos há relação entre experimentar o medo da AIDS e uma percepção realista do seu próprio risco. Ao questionar sua percepção da auto-eficácia, avaliando os recursos disponíveis e seu contexto, o indivíduo depara-se com sua vulnerabilidade e com o medo de ter AIDS (Tabela 6). 
Tabela 6. Relação entre medo e percepção da auto-eficácia (rede de ensino médio de Florianópolis, Itajaí e Balneário Camboriú, 2000) $(n=988)^{*}$.

\begin{tabular}{|c|c|c|c|c|c|c|c|c|}
\hline \multirow{3}{*}{ Escolas } & & & \multicolumn{6}{|c|}{ Você protege-se o suficiente da AIDS } \\
\hline & & & \multicolumn{2}{|c|}{ Sim } & \multicolumn{2}{|c|}{ Não/não sei } & \multicolumn{2}{|c|}{ Total } \\
\hline & & & $n$ & $\%$ & $n$ & $\%$ & $n$ & $\%$ \\
\hline \multirow[t]{3}{*}{ Pública diurna } & Têm muito medo de vir a ter AIDS & Sim & 186 & 49,6 & 50 & 26,9 & 236 & 42,0 \\
\hline & & Não & 189 & 50,4 & 136 & 73,1 & 325 & 58,0 \\
\hline & $\chi^{2}=25,41 \mathrm{gl}=1 p<0,001$ & Subtotal & 375 & 100,0 & 186 & 100,0 & 561 & 100,0 \\
\hline \multirow[t]{3}{*}{ Particular } & Têm muito medo de vir a ter AIDS & Sim & 191 & 59,1 & 47 & 45,6 & 238 & 55,7 \\
\hline & & Não & 133 & 41,0 & 56 & 54,4 & 189 & 44,3 \\
\hline & $\chi^{2}=5,10 \mathrm{gl}=1 p<0,05$ & Subtotal & 324 & 100,0 & 103 & 100,0 & 427 & 100,0 \\
\hline Total & $\chi^{2}=33,4 \mathrm{gl}=1 p<0,001$ & & 699 & 70,7 & 289 & 29,3 & 988 & 100,0 \\
\hline
\end{tabular}

*Entre os alunos da escola pública noturna não houve diferença significativa.

Mas quanto aos alunos que estudam no turno noturno da escola pública, em torno de 60\% declararam não experimentar o sentimento de medo da AIDS, independentemente de considerarem que se protegem ou não.

\section{Conclusão}

Os resultados indicam que tanto o conhecimento sobre os meios da transmissão do HIV quanto a experiência sexual apresentam relação com a atitude sobre o preservativo. A informação sobre a AIDS está ligada a atitudes mais positivas e a experiência sexual a atitudes mais negativas.

A avaliação da vulnerabilidade, no sentido que a empregamos aqui, inclui como componentes variáveis comportamentais, cognitivas e sociais, sendo fruto da coletividade que engloba a família e outros grupos sociais, como a escola, o trabalho, etc.

Os alunos dos períodos noturnos das escolas públicas possuem maior experiência sexual, pois são mais velhos e têm necessidade de exercer trabalho remunerado, o que os coloca mais próximos do ambiente adulto não familiar. Além disso, têm como interlocutores para comunicação sobre sexualidade mais freqüentemente os amigos e menos os pais ou a família, o que constituiu um fator de risco.

Foram observadas diferenças em termos de comportamento entre os alunos das diferentes escolas e turnos escolares. O grupo de alunos com maior vulnerabilidade ao HIV, com comportamento sexual mais arriscado e atitudes menos positivas em relação ao preservativo, foi o do noturno das escolas públicas. Esses achados vão ao encontro dos resultados de Wuo (2003), sobretudo no que diz respeito ao envolvimento emocional (namoro) dificultar a adoção da prática do sexo seguro, ou seja, do uso do preservativo.

Os alunos que dispunham de informação adequada sobre a AIDS apresentaram atitudes mais positivas sobre o preservativo e um comportamento mais adequado de prevenção. O tipo de escola e o turno de estudo, como indicadores de condições socioeconômicas diferenciadas, indicaram que os alunos das escolas públicas que estudam no período noturno são mais vulneráveis à AIDS, embora os alunos das escolas particulares estejam mais envolvidos com outros tipos de risco, como o uso de droga (álcool e maconha) e violência (brigas e destruição de coisas alheias). 0 conhecimento específico do assunto é determinante no posicionamento coerente do adolescente diante do seu ambiente, pois fornece as bases para a ação protetora, e traz implícitas a liberdade e a possibilidade de escolha para o adolescente.

É importante lembrar que o método empregado neste estudo é limitado em alguns aspectos, pois é mediado por um questionário padronizado, por meio do qual se obtêm informações pela observação indireta. Estudos observacionais sobre sexualidade são de difícil operacionalização. Mas novas pesquisas que abordem os adolescentes no contexto de grupos focais e em situação experimental complementariam a compreensão da vulnerabilidade desse grupo diante do HIV/AIDS. 


\section{Referências}

Akkari, A. J. (2001). Desigualdades educativas estruturais no Brasil: entre estado, privatização e descentralização. Educação e Sociedade, 22 (74), 163-189.

Ayres, J. R. C. M. (1996). O jovem que buscamos e o encontro que queremos ser: a vulnerabilidade como eixo de avaliação de ações preventivas do abuso de drogas, DST e AIDS entre crianças e adolescentes. In D. Tozzi, N. L. Santos, C. M. Amaro, E. Almeida, E. J. Silva \& M. L. Pereira (Orgs.), Papel da educação na ação preventiva ao abuso de drogas e às DST/AIDS. São Paulo: Fundação para o Desenvolvimento da Educação.

Ayres, J. R. C. M., França, I. J., Calazans, G. J., \& Saletti, H. C. F. (1999). Vulnerabilidade e prevenção em tempos de AIDS. In R. M. Barbosa, R. Parker. Sexualidades pelo avesso: direitos identidades e poder. São Paulo: Ed. 34.

Bandura, A. (1997). Self-efficacy in changing societies. Cambridge: Cambridge University Press.

Béria, J., \& Barros, A. J. D. (1998). Oito meses depois: o impacto da intervenção entre os adolescentes. In J. Béria (Org.), Ficar, transar...: a sexualidade em tempos de AIDS (pp.111-126). Porto Alegre: Tomo Editorial.

Béria, J., Oliveira, O. M. F., \& Carret, M. L. V. (1998). Adolescentes e HIV/AIDS: Pesquisa formativa em um estudo de intervenção. In J. Béria (Org.), Ficar, transar...: a sexualidade em tempos de AIDS (pp.37-54). Porto Alegre: Tomo Editorial.

Camargo, B. V. (1997). Estudo do conhecimento, das atitudes, e dos aspectos da comunicação relativos a prevenção da AIDS dos estudantes das $3 a s$ séries da Escola Técnica Federal de Santa Catarina (pp.1-16) (Relatório Técnico de Pesquisa). Florianópolis: UFSC/LACCOS.

Camargo, B. V., Botelho, L. J., \& Souza, E. S. B. (2001). AIDS, sexualidade e atitudes sobre a proteção contra o HIV: um estudo descritivo com adolescentes do nível médio da rede de ensino (Florianópolis, Itajaí e Balneário Camboriú) (pp.1-42) (Relatório Técnico de Pesquisa). Florianópolis: UFSC/LACCOS.

Camargo, B. V., Hias, F. M. S., \& Machado, P. V. (2002). O impacto da informação preventiva da AIDS: estudo experimental dos efeitos da leitura de panfletos informativos sobre o conhecimento e a atitude relativos à transmissão e proteção do HIV (Relatório técnico de pesquisa). Florianópolis: UFSC/LACCOS.

Casassus, J. (2002). A escola e a desigualdade. Brasília: Plano Editorial.
Di lorio, C., Kelley, M., \& Hockenberry-Eaton, M. (1999). Communication about sexual issues: mothers fathers and friends. Journal of Adolescent Health, 24 (3), 181-189.

Fazio, R. H., \& Zanna, M. P. (1981). Direct experience and attitude-behavior consistency. Advances in Experimental Social Psychology, 14 (1), 161-202.

Gebhart, W. A., Kuyper, L., \& Greunsven, G. (2003). Need for intimacy in relationships and motives for sex as determinants of adolescent condom use. Journal of Adolescent Health, 33 (3), 154-167.

Giacomozzi, A. I. (2004). Confiança no parceiro e proteção frente ao HIV:estudo de representações sociais. Dissertação de mestrado não-publicada, Universidade Federal de Santa Catarina, Florianópolis.

Ministério da Saúde. Boletim Epidemiológico DST/Aids-janeiro a dezembro de 2003. Acessado em abril 16, 2004, disponível em: www.aids.gov.br/dadosdeaids

Lima, M. L. (1998). Fatores sociais na percepção de riscos. Psicologia, 12 (1), 11-28.

Mann, J. (Org.) (1993). A Aids no mundo. Rio de Janeiro: Relume Dumará.

Nicolson, P., \& Burr, J. (2003). What is 'normal' about women's (hetero)sexual desire and orgasm? a report of an in-depth interview study. Social Science and Medicine, 57 (2003), 1735-1745.

Parker, R. G. (1991). Corpos, prazeres e paixões: a cultura sexual no Brasil contemporâneo. São Paulo: Best Seller.

Rodrigues, A., Assmar, E. M. L., \& Jablonski, B. (1999). Psicologia social. Petrópolis: Vozes.

Rosenberg, A. (1986). Democracia e socialismo: história política dosúltimos cento e cinqüenta anos (1789-1937). São Paulo: Global Ed.

Rua, M. G., \& Abramovay, M. (2001). Avaliação das ações de prevenção às DST/AIDS e uso indevido de drogas nas escolas de ensino fundamental e médio em capitais brasileiras. Brasília: Unesco.

Tinsley, B. J., Lees, N. B., \& Sumartojo, E. (2004). Child and adolescent HIV risk: familial and cultural perspectives. Journal of Family Psychology, 18 (1), 208-224.

Wuo, M. (2003). Aids na escola: os contextos sociais e as representações sociais de estudantes de ensino médio. Tese de doutorado não-publicada, Pontifícia Universidade Católica de Campinas.

Recebido em: 14/12/2005

Versão final reapresentada em: 10/4/2006

Aprovado em: 26/6/2006 
